American Journal of Applied Sciences 6 (5): 956-963, 2009

ISSN 1546-9239

(C) 2009 Science Publications

\title{
Application of the Ant Colony Search Algorithm to Reactive Power Pricing in an Open Electricity Market
}

\author{
A. Ketabi and A. Ali Babaee \\ Department of Electrical Engineering, University of Kashan, Kashan, Iran
}

\begin{abstract}
Developing an accurate and feasible method for reactive power pricing is important in the electricity market. In conventional optimal power flow models the production cost of reactive power was ignored. In this study, the production cost of reactive power was comprised into the objective function of the OPF problem. Then, using ant colony search algorithm, the optimal problem was solved. The IEEE 14-bus system has been used for application of the method. The results from several study cases show clearly the effects of various factors on reactive power price.
\end{abstract}

Key words: Electricity market, cost allocation, reactive power pricing, ant colony search algorithm

\section{INTRODUCTION}

The traditional regulated and monopoly structure of power industry throughout the world is eroding into an open-access and competitive environment.

Thus planning and operation of the utilities are based on the economic principles of open-access markets. In this new environment electric markets are essentially competitive. Until now, effort has been directed primarily toward developing methodologies to determine remuneration for the active power of the generators. Although the investment in electric power generation and the fuel cost represent the most important costs of power system operation, reactive power is becoming more and more important, especially from the view of security and the economic effect caused by $\mathrm{it}^{[1]}$.

As to ancillary services, reactive power compensation and optimization sustains the exchange of electric power greatly as a part of ancillary services. The consumption of the reactive power follows a similar demand against time curve as the active power, especially for motor loads and furnaces. Therefore, the operation and cost allocation of reactive power is very important to the running and management of generation and/or transmission companies ${ }^{[1]}$.

A fixed tariff on the remuneration for reactive power is insufficient to provide a proper signal of reactive power $\operatorname{cost}^{[2]}$. Berg et al. ${ }^{[3]}$ pointed out the limitations of a reactive power price policy based on power factor penalties and suggested the use of economic principles based on marginal theory ${ }^{[4]}$. However, these prices represent a small portion of the actual reactive power price ${ }^{[5-7]}$. Hao and Papalexopoulos ${ }^{[8]}$ note that the reactive power marginal price is typically less than $1 \%$ of the active power marginal price and depends strongly on the network constraints. The cost of reactive power production modeling is difficult because of differences in reactive power generation equipment, local geographical characteristics of reactive power ${ }^{[9]}$. Several applications using a model of the cost of reactive power production have been developed ${ }^{[10-15]}$. However, despite the complexity of the proposed models and results obtained, a precise definition of the cost of reactive power production and the methodology to obtain the cost curves are not very clear.

In a competitive electric market the generators may provide the necessary reactive power compensation if they are remunerated by the service but taking into account the loss of opportunity in the commercialization of active power ${ }^{[12]}$. Static compensators (capacitive and inductive) may be remunerated according to their investment costs and depreciation of their useful lives ${ }^{[13]}$.

To address the above mentioned needs, in present study, both active and reactive power production costs of generators and capital cost of capacitors are considered in the objective function of OPF problem. Then a new method based on the ant colony algorithms and advanced sequential quadratic programming is employed to solve the OPF problem. The IEEE 14-bus system has been used for case study. Different objective functions are applied in the simulation tests to observe their impacts on reactive power prices.

Corresponding Author: A. Ketabi, Department of Electrical Engineering, University of Kashan, Kashan, Iran TeleFax: +98-3615559930 
Am. J. Applied Sci., 6 (5): 956-963, 2009

\section{OBJECTIVE FUNCTION AND CONSTRAINTS}

Objective function is the summation of active and reactive power production costs, produced by generators and capacitor banks:

$$
\mathrm{C}=\sum_{\mathrm{i}=1}^{\mathrm{N}_{\mathrm{g}}}\left[\mathrm{C}_{\mathrm{gpi}}\left(\mathrm{P}_{\mathrm{Gi}}\right)+\mathrm{C}_{\mathrm{gqi}}\left(\mathrm{Q}_{\mathrm{Gi}}\right)\right]+\sum_{\mathrm{j}=1}^{\mathrm{N}_{\mathrm{c}}} \mathrm{C}_{\mathrm{cj}}\left(\mathrm{Q}_{\mathrm{Cj}}\right)
$$

Where:

$\mathrm{N}_{\mathrm{g}} \quad=$ Nnumber of generators

$\mathrm{N}_{\mathrm{c}} \quad=$ Number of buses which capacitor banks are installed

$\mathrm{C}_{\mathrm{gpi}}\left(\mathrm{P}_{\mathrm{Gi}}\right)=$ Active power cost function in $\mathrm{i}^{\text {th }}$ bus

$\mathrm{C}_{\mathrm{gqi}}\left(\mathrm{Q}_{\mathrm{Gi}}\right)=$ Reactive Power cost function in $\mathrm{i}^{\text {th }}$ bus

$\mathrm{C}_{\mathrm{Cj}}\left(\mathrm{Q}_{\mathrm{Cj}}\right)=$ Capital cost function of capacitor bank in $\mathrm{j}^{\text {th }}$ bus

Cost function of active power used in (1) is considered as follows:

$$
\mathrm{C}_{\mathrm{gpi}}\left(\mathrm{P}_{\mathrm{Gi}}\right)=\mathrm{a}+\mathrm{bP}_{\mathrm{Gi}}+\mathrm{cP}_{\mathrm{Gi}}^{2}
$$

The capacity of generators is limited by the synchronous generator armature current limit, the field current limit and the under-excitation limits. Because of these limits, the production of reactive power may require a reduction of real power output. Opportunity cost is the lost benefit of this reduction of real power output of the generator.

Opportunity cost depends on demand and supply in market, so it is hard to determine its exact value. In simplest form opportunity cost can be considered as follows:

$$
\mathrm{C}_{\mathrm{gpi}}\left(\mathrm{Q}_{\mathrm{Gi}}\right)=\left[\mathrm{C}_{\mathrm{gpi}}\left(\mathrm{S}_{\mathrm{Gi}, \max }\right)-\mathrm{C}_{\mathrm{gpi}}\left(\sqrt{\mathrm{S}_{\mathrm{Gi}, \text { max }}^{2}-\mathrm{Q}_{\mathrm{Gi}}^{2}}\right)\right] \cdot \mathrm{k}
$$

Where:

$$
\begin{aligned}
\mathrm{S}_{\mathrm{Gi}, \max }= & \text { Maximum apparent power in } \mathrm{i}^{\text {th }} \text { bus } \\
\mathrm{Q}_{\mathrm{Gi}}= & \text { Reactive power of generator in } \mathrm{i}^{\text {th }} \text { bus } \\
\mathrm{K} & =\text { Reactive power efficiency rate (usually } \\
& \text { between 5-10\%) }
\end{aligned}
$$

Modified triangle method is an alternative strategy for reactive power cost allocation.

According to Fig. 1 we can write:

$$
\begin{aligned}
& \mathrm{P}^{\prime}=\mathrm{P} \cos (\theta)=\mathrm{S}^{2} \cos ^{2}(\theta) \\
& \mathrm{Q}^{\prime}=\mathrm{Q} \sin (\theta)=\operatorname{Sin}^{2}(\theta)
\end{aligned}
$$

Using (4) and (5) we have:

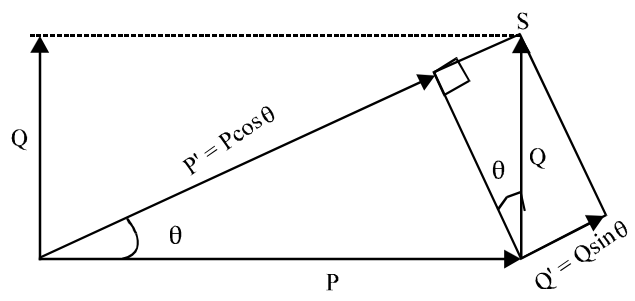

Fig. 1: Modified triangle method for reactive power cost allocation

$$
\begin{aligned}
& \mathrm{P}^{\prime}+\mathrm{Q}^{\prime}=\mathrm{S} \\
& \operatorname{Cost}\left(\mathrm{P}^{\prime}\right)+\operatorname{Cost}\left(\mathrm{Q}^{\prime}\right)=\operatorname{Cost}(\mathrm{S})
\end{aligned}
$$

For expressing active power cost, we replace (4) in (2) as follows:

$$
\begin{aligned}
& \operatorname{Cost}\left(\mathrm{P}^{\prime}\right)=\operatorname{Cost}(\mathrm{P} \cos (\theta)) \\
& =\mathrm{a}+\mathrm{b} \cos (\theta) \mathrm{P}+\cos ^{2}(\theta) \mathrm{P}^{2}=\mathrm{a}+\mathrm{b}^{\prime} \mathrm{P}+\mathrm{c}^{\prime} \mathrm{P}^{2}
\end{aligned}
$$

Using (2) and (5) the new frame of reactive power pricing can be written as given below:

$$
\begin{aligned}
& \operatorname{Cost}\left(Q^{\prime}\right)=\operatorname{Cost}\left(\operatorname{Sin}^{2}(\theta)\right)=\operatorname{Cost}\left(\frac{P}{\cos (\theta)} \sin ^{2}(\theta)\right) \\
& =a+b \sin (\theta) Q+\operatorname{cin}^{2}(\theta) Q^{2}=a+b^{\prime \prime} Q+c^{\prime \prime} Q^{2}
\end{aligned}
$$

It is assumed that the reactive compensators are owned by private investors and installed at some selected buses. The charge for using capacitors is assumed proportional to the amount of the reactive power output purchased and can be expressed as:

$$
\mathrm{C}_{\mathrm{Cj}}\left(\mathrm{Q}_{\mathrm{Cj}}\right)=\mathrm{r}_{\mathrm{j}} \mathrm{Q}_{\mathrm{Cj}}
$$

where, $r_{j}$ and $\mathrm{Q}_{\mathrm{Cj}}$ are the reactive cost and amount purchased, respectively, at location $\mathrm{j}$. The production cost of the capacitor is assumed as its capital investment return, which can be expressed as its depreciation rate. For example, if the investment cost of a capacitor is $\$ 11600 / \mathrm{MVA}$ and their average working rate and life span are $2 / 3$ and 15 years, respectively, the cost or depreciation rate of the capacitor can be calculated by:

$$
\begin{aligned}
r_{j} & =\frac{\text { investment cost }}{\text { operating hours }} \\
& =\frac{\$ 11600}{15 \times 365 \times 24 \times 2 / 3}=\frac{\$ 0.1324}{\text { MVAh }}
\end{aligned}
$$

In the reactive power cost optimization, the active power output of generators is specified. The bus voltage, the reactive power output of generators and 
capacitors are the control variables. The equality and inequality constraints include the load flow equations, active and reactive power output of generators, reactive power output of capacitors and the bus voltage limits at the normal operating condition, as shown below:

Load flow equations:

$$
\begin{aligned}
& \mathrm{P}_{\mathrm{Gi}}-\mathrm{P}_{\mathrm{Di}}-\sum\left|\dot{\mathrm{V}}_{\mathrm{i}}\right|\left|\dot{\mathrm{V}}_{\mathrm{j}}\right|\left|\mathrm{Y}_{\mathrm{ij}}\right| \cos \left(\theta_{\mathrm{ij}}+\delta_{\mathrm{j}}-\delta_{\mathrm{i}}\right)=0 \\
& \mathrm{Q}_{\mathrm{Gi}}-\mathrm{Q}_{\mathrm{Di}}-\sum\left|\dot{\mathrm{V}}_{\mathrm{i}}\right|\left|\dot{\mathrm{V}}_{\mathrm{j}}\right|\left|\mathrm{Y}_{\mathrm{ij}}\right| \sin \left(\theta_{\mathrm{ij}}+\delta_{\mathrm{j}}-\delta_{\mathrm{i}}\right)=0
\end{aligned}
$$

Active and reactive power generation limits:

$$
\begin{aligned}
& \mathrm{P}_{\mathrm{Gi} \text { min }} \leq \mathrm{P}_{\mathrm{Gi}} \leq \mathrm{P}_{\mathrm{Gi} \text { max }} \\
& \mathrm{Q}_{\mathrm{Gi} \text {,min }} \leq \mathrm{Q}_{\mathrm{Gi}} \leq \mathrm{Q}_{\mathrm{Gi} \text {,max }}
\end{aligned}
$$

Capacitor reactive power generation limits:

$$
0 \leq \mathrm{Q}_{\mathrm{Cj}} \leq \mathrm{Q}_{\mathrm{Cj}, \max }
$$

Transmission line limit:

$$
\begin{aligned}
& \left|P_{i j}\right| \leq P_{i j, \max }, P_{i j}=\left|\dot{V}_{i}\right|\left|\dot{V}_{j}\right|\left|Y_{i j}\right| \\
& \cos \left(\theta_{i j}+\delta_{j}-\delta_{i}\right)-\left|\dot{V}_{i j}\right|^{2}\left|Y_{i j}\right| \cos \theta_{i j}
\end{aligned}
$$

Bus voltage limits:

$$
\mathrm{V}_{\mathrm{i}, \min } \leq\left|\mathrm{V}_{\mathrm{i}}\right| \leq \mathrm{V}_{\mathrm{i}, \max }
$$

Where:

$\mathrm{P}_{\mathrm{Di}}$ and $\mathrm{Q}_{\mathrm{Di}} \quad=$ The specified active and reactive demand at $i^{\text {th }}$ load bus, respectively

$\mathrm{Y}_{\mathrm{ij}} \angle \theta_{\mathrm{ij}} \quad=$ The element of the admittance matrix

$\dot{\mathrm{V}}_{\mathrm{i}}=\mathrm{V}_{\mathrm{i}} \angle \delta_{\mathrm{i}} \quad=$ The bus voltage at $\mathrm{i}^{\text {th }}$ bus

$\mathrm{P}_{\mathrm{Gi} \text { min }}$ and $\mathrm{P}_{\mathrm{Gi} \text { max }}=$ The lower and upper limits of active power generation at $\mathrm{i}^{\text {th }}$ generator, respectively

$\mathrm{Q}_{\mathrm{Gi}, \min }$ and $\mathrm{Q}_{\mathrm{Gi}, \max }=$ The lower and upper limits of reactive power generation at $i^{\text {th }}$ generator, respectively

$\mathrm{Q}_{\mathrm{Cj} \text {,max }} \quad=$ The upper limits of reactive power output of the capacitor

$\mathrm{V}_{\mathrm{i} \text {,min }}$ and $\mathrm{V}_{\mathrm{i}, \max }=$ The lower and upper limits of voltage at $\mathrm{i}^{\text {th }}$ bus, respectively

The general-purpose optimization problem can be expressed as:

$$
\begin{array}{ll}
\min _{\mathrm{x}} \mathrm{f}(\mathrm{x}) & \\
\mathrm{h}_{\mathrm{i}}(\mathrm{X})=0 & \mathrm{i}=1 \cdot 2 \cdot 3 \ldots \mathrm{N}_{\text {eq }} \\
\mathrm{g}_{\mathrm{i}}(\mathrm{X})>0 & \mathrm{i}=1 \cdot 2.3 \ldots . \mathrm{N}_{\text {ueq }}
\end{array}
$$

The corresponding Lagrange function of the problem is formed as:

$$
L(X, \lambda)=f(X)+\sum_{i=1}^{p} \lambda_{i} g_{i}(X)+\sum_{j=1}^{m} \lambda_{p+j} h_{j}(x)
$$

where, $\lambda_{i}$ is the Lagrange multiplier for the $i^{\text {th }}$ constraint.

Based on the above mathematical model the corresponding Lagrangian function of this optimization problem takes the form of (16).

According to microeconomics, the marginal prices for active power and reactive power at $i^{\text {th }}$ bus are $\lambda_{\text {pi }}$ and $\lambda_{\text {qi }}$ respectively and will be taken as the corresponding spot prices in the electricity markets ${ }^{[15]}$ :

$$
\begin{aligned}
& \mathrm{L}=\sum_{\mathrm{i} \in \mathrm{G}}\left[\mathrm{C}_{\mathrm{gpi}}\left(\mathrm{P}_{\mathrm{Gi}}\right)+\mathrm{C}_{\mathrm{ggi}}\left(\mathrm{Q}_{\mathrm{Gi}}\right)\right]+\sum_{\mathrm{j} \in \mathrm{C}} \mathrm{C}_{\mathrm{cj}}\left(\mathrm{C}_{\mathrm{Cj}}\right) \\
& -\sum_{\mathrm{i} \in \mathrm{N}} \lambda_{\mathrm{pi}}\left[\mathrm{P}_{\mathrm{Gi}}-\mathrm{P}_{\mathrm{Di}}-\sum\left|\dot{\mathrm{V}}_{\mathrm{i}}\right|\left|\dot{\mathrm{V}}_{\mathrm{j}}\right|\left|\mathrm{Y}_{\mathrm{ij}}\right| \cos \left(\theta_{\mathrm{ij}}+\delta_{\mathrm{j}}-\delta_{\mathrm{i}}\right)\right] \\
& -\sum_{\mathrm{i} \in \mathrm{N}} \lambda_{\mathrm{qi}}\left[\mathrm{Q}_{\mathrm{Gi}}-\mathrm{Q}_{\mathrm{Di}}-\sum\left|\dot{\mathrm{V}}_{\mathrm{i}}\right|\left|\dot{\mathrm{V}}_{\mathrm{j}}\right|\left|\mathrm{Y}_{\mathrm{ijj}}\right| \sin \left(\theta_{\mathrm{ij}}+\delta_{\mathrm{j}}-\delta_{\mathrm{i}}\right)\right] \\
& +\sum_{\mathrm{i} \in \mathrm{G}} \mu_{\mathrm{pi} \text { max }}\left(\mathrm{P}_{\mathrm{Gi}, \min }-\mathrm{P}_{\mathrm{Gi}}\right)+\sum_{\mathrm{i} \in \mathrm{G}} \mu_{\mathrm{pi}, \max }\left(\mathrm{P}_{\mathrm{Gi}}-\mathrm{P}_{\mathrm{Gi}, \max }\right) \\
& +\sum_{\mathrm{j} \in \mathrm{C}} \mu_{\mathrm{cj}, \min }\left(\mathrm{Q}_{\mathrm{Cj}, \min }-\mathrm{Q}_{\mathrm{Cj}}\right)+\sum_{\mathrm{j} \in \mathrm{c}} \mu_{\mathrm{cj}, \max }\left(\mathrm{Q}_{\mathrm{cj}}-\mathrm{Q}_{\mathrm{cj}, \max }\right) \\
& +\sum_{\mathrm{i} \in \mathrm{G}} \mu_{\mathrm{si}}\left(\mathrm{P}_{\mathrm{Gi}}^{2}+\mathrm{Q}_{\mathrm{Gi}}^{2}-\mathrm{S}_{\mathrm{Gi}, \max }^{2}\right)+\sum_{\mathrm{i} \in \mathrm{N}} \sum_{\substack{\mathrm{j} \in \mathrm{N} \\
\mathrm{j} \neq \mathrm{i}}} \eta_{\mathrm{ijj}}\left(\left|\mathrm{P}_{\mathrm{ij}}\right|-\mathrm{P}_{\mathrm{ij}, \max }\right) \\
& +\sum_{\mathrm{i} \in \mathrm{N}} \mathrm{V}_{\mathrm{i}, \min }\left(\mathrm{V}_{\mathrm{i}, \min }-\left|\mathrm{V}_{\mathrm{i}}\right|\right)+\sum_{\mathrm{i} \in \mathrm{N}} \mathrm{V}_{\mathrm{i}, \max }\left(\left|\mathrm{V}_{\mathrm{i}}\right|-\mathrm{V}_{\mathrm{i}, \max }\right)
\end{aligned}
$$

\section{ANT COLONY ALGORITHM}

Ant Colony Optimization (ACO) method handles successfully various combinatorial complex problems. Dorigo has proposed the first ACO method in his Ph.D. thesis $^{[16]}$. ACO algorithms are developed based on the observation of foraging behavior of real ants. Although they are almost blind animals with very simple individual capacities, they can find the shortest route between their nest(s) and a source of food without using visual cues. They are also capable of adapting to changes in the environment; for example, finding a new shortest path once the old one is no longer feasible due to a new obstacle. The studies by ethnologists reveal 
that such capabilities are essentially due to what is called pheromone trails, which ants use to communicate information among individuals regarding path and to decide where to go. During their trips a chemical trail (pheromone) is left on the ground. The pheromone guides other ants towards the target point. Furthermore, the pheromone evaporates over time (i.e., it loses quantity if other ants lay down no more pheromone). If many ants choose a certain path and lay down pheromones, the quantity of the trail increases and thus this trail attracts more and more ants ${ }^{[17-19]}$. Each ant probabilistically prefers to follow a direction rich in pheromone rather than a poorer one.

The basic ACO method was inspired by the behavior of real ant colonies in which a set of artificial ants cooperate in solving a problem by exchanging information via pheromone deposited on a graph. The basic ACO is often to deal with the combinatorial optimization problems. The Generalized Ant Colony Optimization (GACO) can be used to solve the continuous or discontinuous, nonconvex, nonlinear constrained optimization problems. The characteristics GACO are positive feedback, distributed computation and the use of constructive greedy heuristic. The proposed GACO algorithm has the following feature.

- The points in feasible region are regard as ants. After some iteration, the ants will centralize at the optimum points, one or several. There're two choices for an ant in each iteration: moving to other ants' point or searching in neighborhood

- The iteration would be guided by changing the distribution of intensity of pheromone in feasible region

- The Sequential Quadratic Programming (SQP) is used as neighborhood-searching algorithm to improve the precision of convergence

- The roulette wheel selection and disturbance are used to prevent the sub-optimization in GACO

The convergence property of GACO is studied based on the fixed-point theorem on a complete metric space, presents several sufficient conditions for convergence.

The procedure of a GACO method can be described as follows.

\section{Step 1: Initialization.}

Initial population: An initial population of ant colony individuals $X_{i}(i=1,2, \ldots, N)$ is selected randomly from the feasible region S. Typically, the distribution of initial trials is uniform. The initial ant colony can be written as:

$$
\mathrm{C}^{0}=\left(\mathrm{X}_{1}, \mathrm{X}_{2}, \ldots, \mathrm{X}_{\mathrm{N}}\right)^{\mathrm{T}} \quad \text { for } \mathrm{X}_{\mathrm{i}} \in \mathrm{S}
$$

Intensity matrix: At initialization phase, the elements of trail intensity matrix $\left(\tau_{\mathrm{N} \times \mathrm{N}}\right)$ are set to a constant level: $\tau_{\mathrm{ij}}=\tau_{0}, \tau_{0}>0$.

Number of ants: Let $b(i)(i=1,2, \ldots, N)$ be the number of ants in point $i$ and at the beginning $b(i)=1$.

Ant's visibility: Ant's visibility can be defined as:

$$
\mathrm{D}(\mathrm{k})=2\left(1-\frac{1}{1+\mathrm{e}^{\mathrm{ak} / \mathrm{T}}}\right) \mathrm{D}_{0}
$$

where, $\mathrm{K}$ is the cycles counter and $\mathrm{D}_{0}$ is the upper limit of ant's visibility. With the running of GACO, the visibility $\mathrm{D}(\mathrm{K})$ decreases and the exactitude of search increases gradually. If $\left\|\mathrm{X}_{\mathrm{i}}-\mathrm{X}_{\mathrm{j}}\right\| \leq \mathrm{D}(\mathrm{k})$ then the ants can transfer from point $\mathrm{i}$ to point $\mathrm{j}$.

Where $\|$.$\| is a kind of norm, which is defined as:$

$$
\|\mathrm{X}\|=\operatorname{Max}\left|\mathrm{x}_{\mathrm{i}}\right|_{\text {1i<n }} \quad \mathrm{X}=\left[\mathrm{x}_{1}, \mathrm{x}_{2}, \ldots, \mathrm{x}_{\mathrm{n}}\right]
$$

Step 2: For the ants on the point i $(i=1,2, \ldots N), b(i)>1$, the neighborhood search for transition is defined as:

$$
\mathrm{A}_{\mathrm{i}}=\left\{\mathrm{X}_{\mathrm{j}} \mid\left\|\mathrm{X}_{\mathrm{i}}-\mathrm{X}_{\mathrm{j}}\right\| \leq \mathrm{D}(\mathrm{k})\right\}
$$

If $A_{i} \neq \Phi$ go to step 3, else go to step 4. Here $\Phi$ is empty set.

Step 3: Let $m$ be the quantity of elements in the set $A_{i}$, we set:

$$
\begin{aligned}
& \Phi_{\mathrm{ij}}=\mathrm{F}\left(\mathrm{X}_{\mathrm{i}}\right)-\mathrm{F}\left(\mathrm{X}_{\mathrm{j}}\right) \quad \forall \mathrm{X}_{\mathrm{j}} \in \mathrm{A}_{\mathrm{i}} \\
& \Phi_{\mathrm{ii}}=\frac{1}{\mathrm{~m}}\left(\frac{2}{1+\mathrm{e}^{-\mathrm{ak} / \mathrm{t}}}-1\right) \sum_{\mathrm{X}_{\mathrm{j}} \in \mathrm{A}_{\mathrm{i}}} \Phi_{\mathrm{ij}}
\end{aligned}
$$

where, $F(X)$ is objective function. Transition probability is defined as:

$$
\begin{aligned}
& \mathrm{P}_{0}=\frac{\left(\Phi_{\mathrm{ii}}\right)^{\gamma_{1}}\left(\frac{1}{\mathrm{~m}_{\mathrm{X}_{\mathrm{j}} \in \mathrm{A}_{\mathrm{i}}}} \sum_{\left.\tau_{\mathrm{ij}}\right)}\right)^{\gamma_{2}}}{\left(\Phi_{\mathrm{ii}}\right)^{\gamma_{1}}\left(\frac{1}{\mathrm{~m}_{\mathrm{X}_{\mathrm{j}} \in A_{\mathrm{i}}}} \sum_{\mathrm{i}_{\mathrm{ij}}}\right)^{\gamma_{2}}+\sum_{\mathrm{X}_{\mathrm{j}} \in \mathrm{A}_{\mathrm{i}}}\left(\Phi_{\mathrm{ij}}\right)^{\gamma_{1}}\left(\tau_{\mathrm{ij}}\right)^{\gamma_{2}}} \\
& P_{i j}=\frac{\left(\Phi_{i j}\right)^{\gamma_{1}}\left(\tau_{i j}\right)^{\gamma_{2}}}{\left(\Phi_{i i}\right)^{\gamma_{1}}\left(\frac{1}{m_{X_{j} \in A_{i}}} \sum_{i j}\right)^{\gamma_{2}}+\sum_{\mathrm{X}_{\mathrm{j}} \in A_{i}}\left(\Phi_{i j}\right)^{\gamma_{1}}\left(\tau_{i j}\right)^{\gamma_{2}}}
\end{aligned}
$$


where, $\gamma_{1}$ and $\gamma_{2}$ are parameters that control the relative importance of trail versus visibility. $\mathrm{P}_{0}$ is the probability of neighborhood search. We note that with the decrease of $\mathrm{F}\left(\mathrm{X}_{\mathrm{j}}\right)$ the $\tau_{\mathrm{ij}}$ and $\mathrm{P}_{\mathrm{ij}}$ increase. By (19) and (20) we see:

$$
\sum_{\mathrm{X}_{\mathrm{j}} \in \mathrm{A}_{\mathrm{i}}} \mathrm{P}_{\mathrm{ij}}+\mathrm{P}_{0}=1
$$

The roulette wheel is used for stochastic selection. If the selection result is a $\mathrm{P}_{\mathrm{ij}}$ carry out the update rule 1 .

Update rule 1: Moving an ant from point $\mathrm{i}$ to point $\mathrm{j}$.

$\mathrm{b}(\mathrm{i})=\mathrm{b}(\mathrm{i})-\mathrm{l}, \mathrm{b}(\mathrm{j})=\mathrm{b}(\mathrm{j})+\mathrm{l}, \Delta \tau_{\mathrm{ij}}=\mathrm{P}_{\mathrm{ij}}, \mathrm{X}_{\mathrm{i}} \leftarrow \mathrm{X}_{\mathrm{j}}$ and go to step 5 . rule 2 .

If the selection result is $\mathrm{P}_{0}$, carry out the update

Update rule 2: Carrying out search by Sequential Quadratic Programming (SQP) algorithm in the neighborhood of $\mathrm{X}_{\mathrm{i}}$. The neighborhood defined by:

$$
\mathrm{S}_{\mathrm{X}_{\mathrm{i}}}=\left\{\mathrm{Y} \mid\left\|\mathrm{X}_{\mathrm{i}}-\mathrm{Y}\right\|<\alpha \cdot \mathrm{D}(\mathrm{K})\right\}
$$

where, $\alpha$ is a positive parameter and $\alpha \in(0,1)$. Let the result of neighborhood search be $\mathrm{Y}$, then $\mathrm{X}_{\mathrm{i}} \leftarrow \mathrm{Y}$ and:

$$
\Delta \tau_{\mathrm{ij}}=\frac{\left.\left(\mathrm{F}\left(\mathrm{X}_{\mathrm{i}}\right)-\mathrm{F}(\mathrm{Y})\right)^{\gamma_{1}}\left(\frac{1}{\mathrm{M}_{\mathrm{X}_{\mathrm{j}} \in \mathrm{A}_{\mathrm{i}}}} \sum_{\mathrm{ij}}\right)\right)^{\gamma_{2}}}{\left.\left(\Phi_{\mathrm{ii}}\right)^{\gamma_{1}}\left(\frac{1}{\mathrm{~m}_{\mathrm{X}_{\mathrm{j}} \in \mathrm{A}_{\mathrm{i}}}} \sum_{\mathrm{ij}}\right)\right)^{\gamma_{2}}+\sum_{\mathrm{X}_{\mathrm{j}} \in \mathrm{A}_{\mathrm{i}}}\left(\Phi_{\mathrm{ij}}\right)^{\gamma_{1}}\left(\tau_{\mathrm{ij}}\right)^{\gamma_{2}}}
$$

Go to step 5.

Step 4: Searching in neighborhood quadratic programming (SQP) algorithm. Let the result be $\mathrm{Y}$, carry out the update rule 3 .

Update rule 3: $\mathrm{X}_{\mathrm{i}} \leftarrow \mathrm{Y}, \Delta \tau_{\mathrm{ij}}=\mathrm{r}$, where $\mathrm{r}$ is a positive constant.

Step 5: Updating the trail intensity matrix according to the following formula:

$$
\tau_{\mathrm{ij}}(\mathrm{K}+1)=\rho \tau_{\mathrm{ij}}(\mathrm{k})+\Delta \tau_{\mathrm{ij}} \forall \mathrm{i} \neq \mathrm{j}, \mathrm{X}_{\mathrm{j}} \in \mathrm{A}_{\mathrm{i}}
$$

where, $\rho$ is a coefficient such that (1- $\rho)$ represents the evaporation of trail between time $K$ and $K+1$.

Step 6: After iteration all ants have complete one move, calculate the results for every $\mathrm{Xi} \in \mathrm{C}^{\mathrm{k}}$. Here $\mathrm{C}^{\mathrm{k}}$ is the ant colony in $\mathrm{K}$ iterations:
- If dissatisfying the convergence condition, cancel the result from step 2-4 and go to step 2

- If the results are not changed after NI iterations, disturb the ant colony by increasing the visibility and neighborhood of search. Here NI is a coefficient

- If $\mathrm{K}<\mathrm{T}, \mathrm{K}=\mathrm{K}+1$ then go to step 2, else print best result and stop

\section{TEST SYSTEM AND SIMULATION RESULTS}

In this research IEEE 14-bus test system is used to test the proposed measurement placement algorithm. A schematic of this test system is shown in Fig. 2 and its total data are provided from ${ }^{[15]}$. There are three generators on buses 1,2 and 9 respectively. The nominal apparent power output of each generator is I25 MVA. The lower and upper limits of power output are $20 \mathrm{MW}$ and $125 \mathrm{MW}$. The active power production cost of each generator is:

$$
\mathrm{C}_{\mathrm{gpi}}\left(\mathrm{P}_{\mathrm{Gi}}\right)=75+750 \mathrm{P}_{\mathrm{Gi}}+420 \mathrm{P}_{\mathrm{Gi}}^{2}(\$ / \mathrm{hr})
$$

All the parameters stated here are in per unit on a 100 MVA base. There are capacitors installed on bus 5 with the total capacity of 50 MVA. We assume the reactive power output can be adjusted continuously.

The other system operation limits are:

- Transmission limit: $\left|\mathrm{P}_{\mathrm{ij}}\right| \leq 1.8$

- Voltage limit: $0.95 \leq\left|V_{\mathrm{i}}\right| \leq 1.05$

- $\quad$ Swing bus settings: $\mathrm{V}_{1}=1.05$ and $\delta_{1}=0$

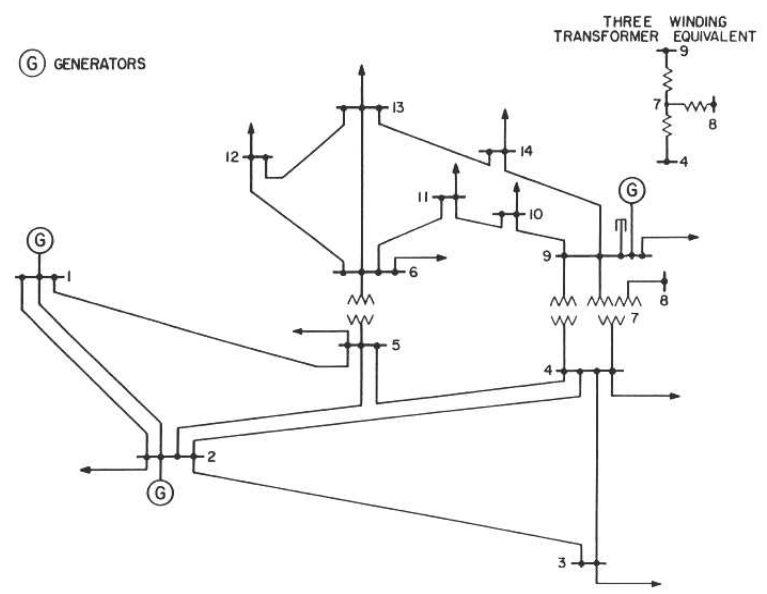

Fig. 2: IEEE 14-bus test system 
Am. J. Applied Sci., 6 (5): 956-963, 2009

Table 1: Test results of cases 1-4 based on opportunity cost

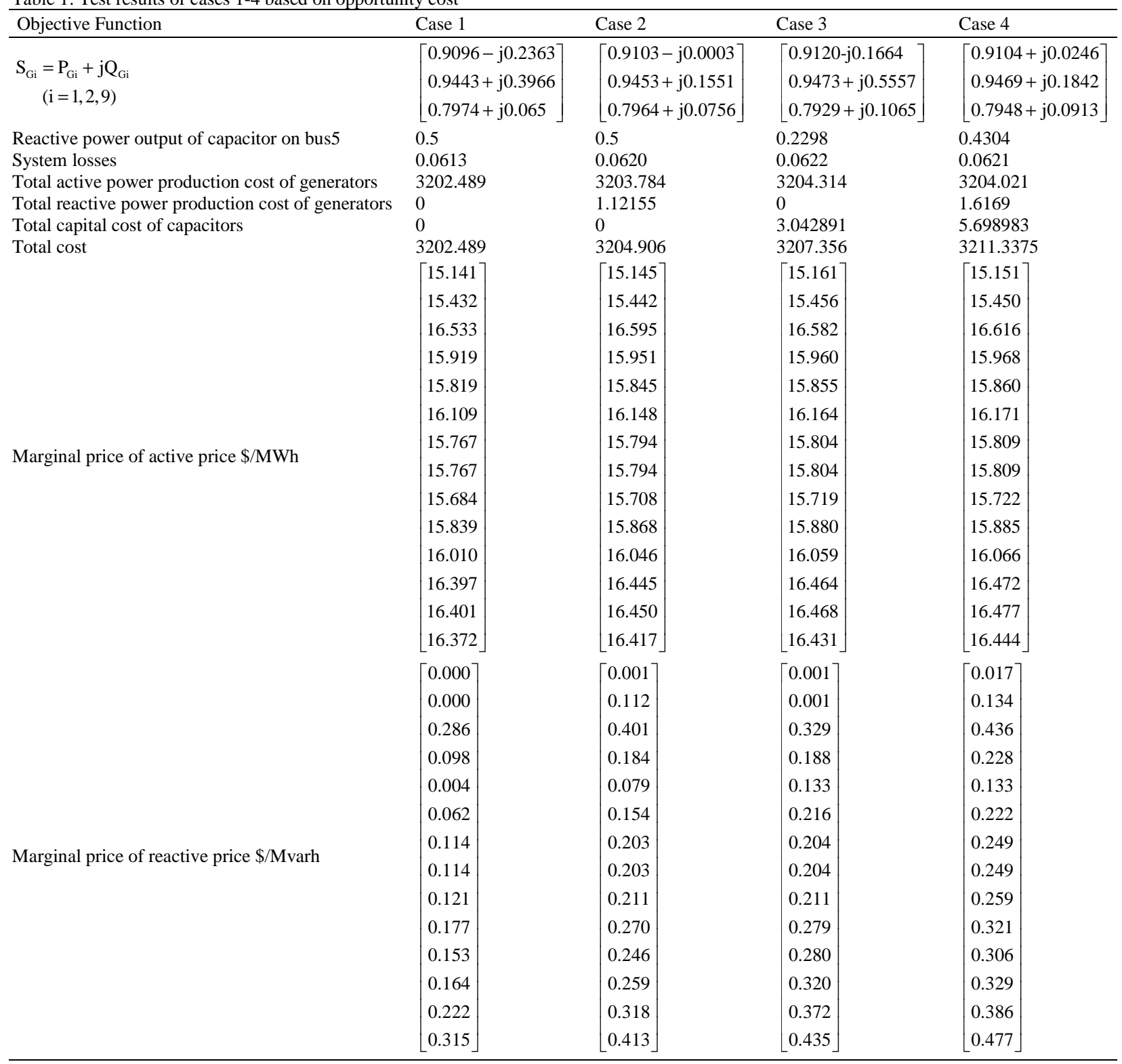

In order to study the impacts of various factors on the marginal price of reactive power, seven cases are studied:

- The objective function has only the first item of (1)

- The objective function has only the first two items with capacitor cost neglected

- The objective function has only the first and the third items with reactive power production cost of generators neglected

- The objective function has all the three items as described in (1)
The computer test results for cases 1 to 4 based on opportunity cost and modified triangle method for reactive power cost allocation are listed in Table 1 and 2 , respectively. The four cases are used to study the impacts of OPF objective functions on reactive power marginal price (RPMP).

According to Table 1 and 2, the following results are obtained:

- The total active power production cost and the active power marginal prices at various buses have only small changes when the objective function changes 
Am. J. Applied Sci., 6 (5): 956-963, 2009

Table 2: Test results of cases 1-4 based on modified triangle method

\begin{tabular}{|c|c|c|c|c|}
\hline Objective Function & Case 1 & Case 2 & Case 3 & Case 4 \\
\hline \multirow{3}{*}{$\begin{array}{c}\mathrm{S}_{\mathrm{Gi}}=\mathrm{P}_{\mathrm{Gi}}+\mathrm{jQ}_{\mathrm{Gi}} \\
(\mathrm{i}=1,2,9)\end{array}$} & {$[1.014-\mathrm{j} 0.165$} & {$[0.9006-\mathrm{j} 0.025$} & {$[1.014-\mathrm{j} 0.165$} & {$[0.9002+\mathrm{j} 0.0154$} \\
\hline & $0.8611+\mathrm{j} 0.7294$ & $0.954+\mathrm{j} 0.11869$ & $0.8611+\mathrm{j} 0.7294$ & $0.9566+\mathrm{j} 0.1965$ \\
\hline & $0.7811+\mathrm{j} 0.173$ & $0.7971+\mathrm{j} 0.0683$ & $0.7811+\mathrm{j} 0.173$ & $0.795+\mathrm{j} 0.089$ \\
\hline Reactive power output of capacitor on bus 5 & 0 & 0.5 & 0 & 0.4289 \\
\hline System losses & 0.0662 & 0.0617 & 0.662 & 0.0618 \\
\hline Total active power production cost of generators & 2886.736 & 3171.453 & 2886.736 & 3166.595 \\
\hline Total reactive power production cost of generators & 0 & 257.392 & 0 & 262.967 \\
\hline Total capital cost of capacitors & 0 & 0 & 0 & 5.67859 \\
\hline \multirow[t]{8}{*}{ Total cost } & 3202.489 & 3428.846 & 2886.736 & 3435.241 \\
\hline & {$[16.1120]$} & {$[15.0621]$} & {$[16.1120]$} & {$[15.0606]$} \\
\hline & 14.0782 & 15.3523 & 14.0782 & 15.3555 \\
\hline & 14.3715 & 16.4938 & 14.3715 & 16.5134 \\
\hline & 14.7567 & 15.8573 & 14.7567 & 15.8729 \\
\hline & 14.9852 & 15.7530 & 14.9852 & 15.7655 \\
\hline & 15.0024 & 16.0539 & 15.0024 & 16.0763 \\
\hline & 14.6970 & 15.7009 & 14.6970 & 15.7143 \\
\hline \multirow{13}{*}{ Marginal price of active price $\$ / M W h$} & 14.6970 & 15.7009 & 14.6970 & 15.7144 \\
\hline & 14.6624 & 15.6155 & 14.6624 & 15.6277 \\
\hline & 14.7433 & 15.7749 & 14.7433 & 15.7903 \\
\hline & 14.8777 & 15.9522 & 14.8777 & 15.9716 \\
\hline & 15.2723 & 16.3486 & 15.2723 & 16.3783 \\
\hline & 15.4199 & 16.3535 & 15.4199 & 16.3872 \\
\hline & 15.2009 & 16.3211 & 15.2009 & 16.3701 \\
\hline & {$[2.5378]$} & {$[0.0014]$} & {$[2.5378]$} & {$[0.0009]$} \\
\hline & 4.8973 & 0.0998 & 4.8973 & 0.1204 \\
\hline & 3.9693 & 0.3888 & 3.9693 & 0.4272 \\
\hline & 3.1288 & 0.1780 & 3.1288 & 0.2284 \\
\hline & 2.6011 & 0.0739 & 2.6011 & 0.1324 \\
\hline & 2.1705 & 0.1447 & 2.1705 & 0.2488 \\
\hline \multirow{8}{*}{ Marginal price of reactive price $\$ /$ Mvarh } & 2.8925 & 0.1982 & 2.8925 & 0.2703 \\
\hline & 2.8925 & 0.1982 & 2.8925 & 0.2703 \\
\hline & 2.7661 & 0.2072 & 2.7661 & 0.2911 \\
\hline & 2.6321 & 0.2647 & 2.6321 & 0.3525 \\
\hline & 2.3893 & 0.2393 & 2.3893 & 0.3350 \\
\hline & 1.9138 & 0.2492 & 1.9138 & 0.3608 \\
\hline & 1.7177 & 0.3084 & 1.7177 & 0.4229 \\
\hline & [2.2207] & {$[0.4060]$} & {$[2.2207]$} & {$[0.5491]$} \\
\hline
\end{tabular}

- For each test case, active power marginal prices at various buses are in the same order while the RPMP fluctuates significantly from bus to bus. Generally the active power marginal price is much higher than the RPMP at a certain bus. In our case it is about 100 times as much as RPMP under normal conditions

- The total reactive power production cost changes apparently along with the objective function change. Although the cost is small, it can accumulate into a large amount

- When the capacitor cost and/or the reactive power generation cost is neglected, the corresponding reactive power source bus(es) will have zero or very little RPMP(s) for the free reactive power available locally. The nearby buses also get benefits and have small RPMPs. For example bus 6 of case 2, which is close to bus 5 where the capacitor is installed, has much smaller RPMP as compared with bus 14 which is far from reactive power sources. When all 3 kinds of reactive power production cost are taken into consideration, the corresponding RPMP increases noticeably (case 4), which gives the load an incentive to reduce its reactive power demand. Besides, the revenue to the reactive power producers will encourage them to invest and provide enough reactive power 
- When the modified triangular method is used for reactive power pricing, the corresponding RPMP at all bus increases noticeably

- The proposed method based on the ant colony algorithms and advanced sequential quadratic programming capable to find global optimum solution for the OPF problem

\section{CONCLUSIONS}

In this study the reactive power marginal price is studied in detail. Both active and reactive power production costs of generators and capital cost of capacitors are considered in the objective function of OPF problem. Then a new method based on the ant colony algorithms and advanced sequential quadratic programming is employed to solve the OPF problem.

The IEEE 14-bus system was used to test the validity of the methodology, considering four objective functions. Test results may confirm that participation of the generators in the reactive power market is important for the participants of a competitive electric market.

It has been observed that the reactive power marginal price is typically less than $3 \%$ of the corresponding active power marginal price.

Based on this study the major conclusions of this work are:

- The reactive power production cost and the capital investment of capacitors should be considered in reactive power spot pricing for their noticeable impacts on reactive power marginal price

- Reactive power marginal cost can serve as a system index related to the urgency of the reactive power supply and system voltage support and an incentive to improve load power factor and reduce reactive power demand

- When the modified triangular method is used for reactive power pricing, the corresponding RPMP at all bus increases noticeably

\section{REFRENCES}

1. Loi Lei Lai, 2001. Power System Restructuring and Deregulation. John Wiley, http://www.wiley.com.

2. Berg, S.V., J. Adams and B. Niekum, 1983. Power factors and the efficient pricing and production of reactive power. Energy J., 4: 93-102.

3. Schweppe F.C., M.C. Caramanis, R.D. Tabors and R.E. Bohn, 2000. Spot Pricing of Electricity. Kluwer, MA, USA.

4. Baughman, M.L. and S.N. Siddiqi, 1991. Real-time pricing of reactive power: Theory and case study results. IEEE Trans. Power Syst., 6: 23-29. DOI: $10.1109 / 59.131043$.

5. El-Keib, A.A. and X. Ma, 1997. Calculating shortrun marginal costs of active and reactive power production. IEEE Trans. Power Syst., 12: 559-565. DOI: $10.1109 / 59.589604$.
6. Chattopadhyay, D., K. Bhattacharya and J. Parikh, 1995. Optimal reactive power planning and its spot-pricing: An integrated approach. IEEE Trans. Power Syst., 10: 2014-2020. DOI: $10.1109 / 59.476070$.

7. Li, Y.Z. and A.K. David, 1994. Wheeling rates of reactive power flow under marginal cost pricing. IEEE Trans. Power Syst., 9: 1263-1269. DOI: 10.1109/59.336141.

8. Hao, S. and A. Papalexopoulos, 1997. Reactive power pricing and management. IEEE Trans. Power Syst., 12: 95-104. DOI: 10.1109/59.574928.

9. Miller, T.J., 1982. Reactive power control in electric systems. Wiley, NJ, USA.

10. Dandachi, N.H., M.J. Rawlins,, 0. Alsac, M. Paris and, B. Stott, 1996. OPF for reactive pricing studies on the NGC system. IEEE Trans. Power Syst., 11: 226-232. DOI: 10.1109/59.486099.

11. Choi, J.Y., S.H. Rim and J.K. Park, 1998. Optimal real time pricing of real and reactive powers. IEEE Trans. Power Syst., 13: 1226-1231. DOI: 10.1109/59.736234.

12. Gil, J.B., T.G. San Roman, J.A. Rios and P.S. Martin, 2000. Reactive power pricing: A conceptual framework for remuneration and charging procedures. IEEE Trans. Power Syst., 15: 483-489. DOI: 10.1109/59.867129.

13. Lamont, J.W. and J. Fu, 1999. Cost analysis of reactive power support. IEEE Trans. Power Syst., 14: 890-896. DOI: 10.1109/59.780900.

14. Zhao, Y., M.R. Irving and Y. Song, 2005. A cost allocation and pricing method for reactive power service in the new deregulated electricity market environment. In: IEEE/PES Transmission and Distribution Conference Asia and Pacific, 1: 6, DOI: 10.1109/TDC.2005.1547186.

15. Chung, C.Y., T.S. Chung, C.W. Yu and X.J. Lin, 2004. Cost-based reactive power pricing with voltage security consideration in restructured power systems. Electric Power systems Research, 70: 85-91, DOI 10.1016/j.epsr.2003.11.002.

16. Dorigo, M., 1992. Optimization, learning and natural algorithms. Ph.D Thesis, Politecnico de Milano, Italy.

17. Dorigo, M., V. Maniezzo and A. Colorni, 1996. Ant system: optimization by a colony of cooperating agents. IEEE Trans. Syst. Man Cybernet., 26: 29-41. DOI: 10.1109/3477.484436.

18. Dorigo, M., G.D.Caro and L.M Gambardella, 1999. Ant's algorithm for discrete optimization. Artificial Life, 5: 137-172.

19. Vlachogiannis, J.G., N.D. Hatziargyriou and K.Y. Lee, 2005. Ant colony system-based algorithm for constrained load flow problem. IEEE Trans. Power Syst., 20: 1241-1249. DOI: 10.1109/TPWRS.2005.851969. 